\title{
Oral adverse events due to zinc deficiency after pancreaticoduodenectomy requiring continuous intravenous zinc supplementation: a case report and literature review
}

\author{
Hironobu Hata ${ }^{1,2^{*} \mathbb{C}}$, Yojiro Ota ${ }^{1 \wedge}$, Katsuhiko Uesaka $^{3} \mathbb{D}$, Yutaka Yamazaki $^{4}$, Tsubasa Murata $^{5}$, Chika Murai $^{6}$,
} Kazuhito Yoshikawa ${ }^{6}, K^{\prime}$ jeni Imamachi ${ }^{2}$, Takashi Yurikusa ${ }^{1}$ and Yoshimasa Kitagawa ${ }^{6}$

\begin{abstract}
Background: Zinc is mainly absorbed in the duodenum and proximal jejunum, which are removed during pancreaticoduodenectomy (PD). Little is known about the adverse oral events and skin disorders caused by zinc deficiency after PD. Herein, we reviewed studies on the development of zinc deficiency after PD and reported about a patient with zinc deficiency after PD who required home intravenous zinc replacement.

Case presentation: A 73-year-old woman with glossitis, taste disorder, and acrodermatitis enteropathica-like eruption on her fingers presented to the Division of Dentistry and Oral Surgery 69 days after PD. Her serum zinc level markedly decreased to $30 \mu \mathrm{g} / \mathrm{dL}$. Oral zinc administration was inadequate to treat hypozincemia after PD; therefore, multi-trace elements were injected intravenously during readmission. Her serum zinc levels recovered, and her lesions gradually improved. Furthermore, a central venous port was implanted to maintain normal serum zinc levels, and she continued self-injecting zinc at home.

Conclusions: Zinc deficiency after PD rarely occurs. The clinical oncologist community, including dentists responsible for the oral care of cancer patients, should be aware of the oral adverse events, such as dysgeusia, glossitis, and oral pain, associated with zinc deficiency after cancer surgery and that induced by chemotherapy or head and neck radiation therapy.
\end{abstract}

Keywords: Zinc deficiency, Dysgeusia, Pancreaticoduodenectomy, Total parenteral nutrition, Case report

\section{Background}

Zinc is an essential trace element for humans, which, when deficient, can cause various pathological conditions, such as dermatitis, hair loss, anemia, dysgeusia, impaired development, gonadal dysfunction, and wound healing disorders $[1,2]$. The role of zinc in taste functions

\footnotetext{
*Correspondence: hatabooh@gmail.com

${ }^{1}$ Division of Dentistry and Oral Surgery, Shizuoka Cancer Center Hospital, Shizuoka, Japan

Full list of author information is available at the end of the article Yojiro Ota: Deceased 29 June 2013
}

is appreciable at various levels of body organization, such as taste buds and the taste sensation transmission [3]. Zinc deficiency secondary to any etiology leads to taste disturbances; thus, zinc depletion is corrected for patients presenting with taste imbalances [4-7]. It has been observed in vivo that zinc administration improves decreased taste bud cell proliferation caused by zinc deficiency [8]. Zinc administration improves taste in 50-82\% of patients suffering from taste disorders [9]. Dysgeusia during cancer treatment is mainly reported in systemic chemotherapy and in surgery and radiation therapy for 
head and neck cancer [10]. However, there are a few reports of taste disorders secondary to zinc deficiency associated with surgery in other regions of the body.

Pancreaticoduodenectomy (PD) is the standard operation for periampullary cancers. Zinc is primarily absorbed in the duodenum and proximal jejunum, which are mostly resected during PD $[11,12]$ and may result in nutritional sequelae due to zinc deficiency [13]. Armstrong et al. reported that the incidence of zinc deficiency after PD is 50\% [14]. Yu et al. [15] reported that $68 \%$ of the patients in their study had low serum zinc levels, and $43 \%$ exhibited clinical symptoms related to zinc deficiency following PD. However, the frequency of taste disorders was not described in either study. The incidence of zinc deficiency with acrodermatitis enteropathica after PD is approximately $0.3 \%$ in a high-volume hospital [13].

Little is known about the adverse oral events and skin disorders caused by zinc deficiency after PD. Therefore, we report a patient who experienced zinc deficiency with dysgeusia, glossitis, and acrodermatitis enteropathicalike eruption after PD.

\section{Case presentation}

A 73-year-old woman with pancreatic head adenocarcinoma underwent pancreatoduodenectomy (PD) at the Division of Hepato-Biliary-Pancreatic Surgery, Shizuoka Cancer Center Hospital, Shizuoka, Japan, in July 2005. The patient's height, body weight, and body mass index were $154 \mathrm{~cm}, 56 \mathrm{~kg}$, and $23.6 \mathrm{~kg} / \mathrm{m}^{2}$, respectively. The patient was discharged 40 days postoperatively; however, approximately 1 month after discharge, she visited the hospital's Division of Dentistry and Oral Surgery with a chief complaint of tongue pain with dysgeusia. The first examination revealed glossitis characterized by complete atrophy of the lingual papillae, which became erythematous; this is a symptom of glossitis (Fig. 1a).
Furthermore, remarkable taste disorder (hypogeusia) and oral pain were reported. The angle of the mouth had stomatitis with erosive changes. The extremities showed acrodermatitis enteropathica-like eruption and abnormal keratinization (Fig. 1b). Blood test results showed hypoproteinemia and hypoalbuminemia (total protein (TP) $5.1 \mathrm{~g} / \mathrm{dL}$, albumin (ALB) $2.4 \mathrm{~g} / \mathrm{dL}$ ) (Table 1). Examination of trace elements showed remarkably lower serum zinc and copper levels $(30 \mu \mathrm{g} / \mathrm{dL}$ and $40 \mu \mathrm{g} / \mathrm{dL}$, respectively) (Table 1). We diagnosed malnutrition, dysgeusia, glossitis, angular cheilitis, and acrodermatitis enteropathica due to zinc deficiency. However, she had no obvious frequent diarrhea or steatorrhea.

Initially, we orally administered $150 \mathrm{mg}$ of Promac ${ }^{\circledR}$ granules 15\% (polaprezinc, ZERIA Pharmaceutical Co., Ltd, Japan) per day (total zinc dose, $34 \mathrm{mg} /$ day) to treat

Table 1 Data of blood tests at the time of initial examination

\begin{tabular}{lll}
\hline Parameter & Reference limits & $\begin{array}{l}\text { Initial } \\
\text { examination }\end{array}$ \\
\hline Total protein & $6.3-8.0 \mathrm{~g} / \mathrm{dL}$ & 5.1 \\
Albumin & $3.9-4.9 \mathrm{~g} / \mathrm{dL}$ & 2.4 \\
White blood cell & $3.3-8.210^{3} / \mu \mathrm{L}$ & 7.03 \\
Red blood cell & $376-50010^{4} / \mu \mathrm{L}$ & 400.0 \\
Hemoglobin & $11.5-14.7 \mathrm{~g} / \mathrm{dL}$ & 12 \\
Hematocrit & $34.5-44.3 \%$ & 36.2 \\
Platelets & $10^{6} / \mu \mathrm{L}$ & 16.7 \\
Aspartate aminotransferase & $7-38 \mathrm{IU} / \mathrm{L}$ & 45 \\
Alanine aminotransferase & $4-44 \mathrm{IU} / \mathrm{L}$ & 46 \\
Alkaline phosphatase & $100-330 \mathrm{IU} / \mathrm{L}$ & 368 \\
Carcinoembryonic antigen & $<5.0 \mathrm{ng} / \mathrm{mL}$ & 18 \\
Colorectal carcinoma antigen $19-9$ & $<37.0 \mathrm{U} / \mathrm{mL}$ & 15 \\
Zinc & $80-140 \mu \mathrm{g} / \mathrm{dL}$ & 30 \\
Copper & $60-130 \mu \mathrm{g} / \mathrm{dL}$ & 40
\end{tabular}

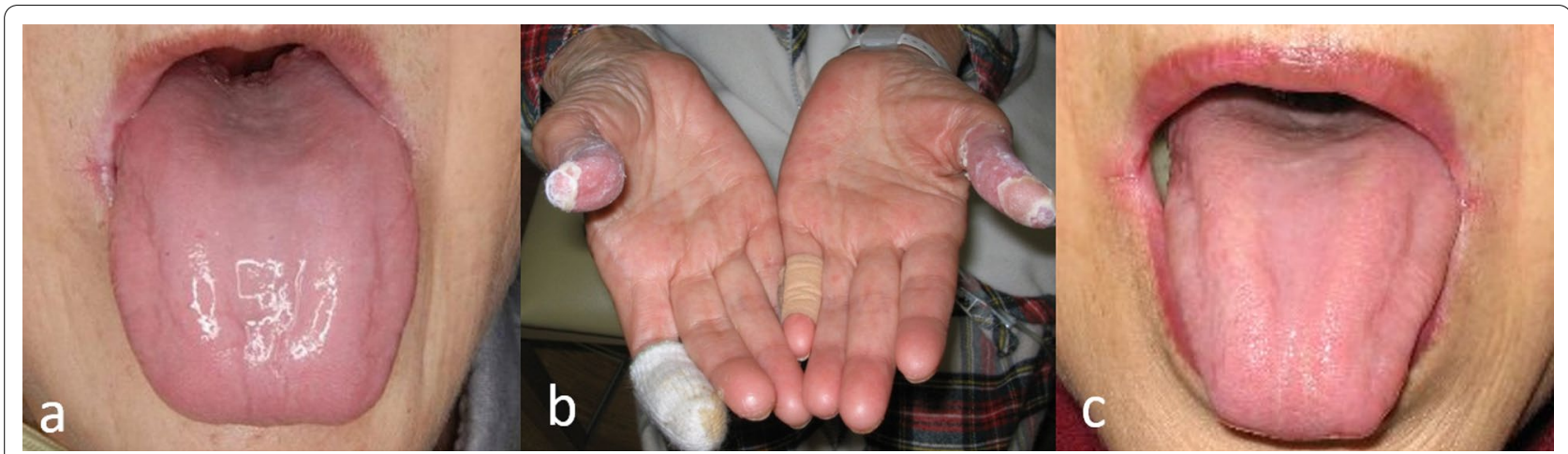

Fig. 1 a Glossitis with atrophy of the lingual papillae and erythema. b Picture of the bilateral thumbs showing acrodermatitis enteropathica-like eruption and abnormal keratinization. c Picture showing improved atrophy of the lingual papillae as a result of proper zinc supplementation, but refractory angular cheilitis 
the zinc deficiency. However, due to the insufficient effectiveness of the replacement therapy, we additionally administered multi-trace elements (MTEs) for high-calorie infusions. Elemenmic ${ }^{\circledR}$ (Ajinomoto Co Inc, Japan) was administered intravenously, one ampule of which contained elemental iron (Fe) $35 \mu \mathrm{mol}$, manganese $(\mathrm{Mn}) 1 \mu \mathrm{mol}$, zinc $(\mathrm{Zn}) 60 \mu \mathrm{mol}(=4 \mathrm{mg})$, copper (Cu) $5 \mu \mathrm{mol}$, and iodine (I) $1 \mu \mathrm{mol}$; this was administered twice a week for 2 weeks as an outpatient treatment. However, the intravenous replacement therapy was similarly inadequate at this dosing interval and did not provide sufficient improvement in the serum copper and zinc values. The blood test results 4 months after PD were as follows: TP, $4.4 \mathrm{~g} / \mathrm{dL} ; \mathrm{ALB}, 2.0 \mathrm{~g} / \mathrm{dL}$; $\mathrm{Zn}, 34 \mu \mathrm{g} / \mathrm{dL}$; and $\mathrm{Cu}, 28 \mu \mathrm{g} / \mathrm{dL}$; the patient required nutritional management during hospitalization with total parenteral nutrition (TPN) (Fig. 2 arrow a). An improvement was observed in the zinc level $(99 \mu \mathrm{g} /$ $\mathrm{dL})$ and copper level $(204 \mu \mathrm{g} / \mathrm{dL})$ after 20 days of administering one ampule of Elemenmic ${ }^{\circledR}$ per day. Concurrently, her tongue pain and dysgeusia gradually improved. Because of a similar improvement in her nutritional status, she completed TPN (TP $5.1 \mathrm{~g} /$ dL, ALB 2.5 g/dL, Zn $99 \mu \mathrm{g} / \mathrm{dL}, \mathrm{Cu} 204 \mu \mathrm{g} / \mathrm{dL}$ ). A central venous catheter (CVC) inserted after admission was removed, and she was discharged 20 days after the second admission. On this occasion, intravenous zinc replacement therapy was discontinued.

One month after discharge, the serum zinc level decreased sharply, her oral pain increased again, and she had reduced food intake ( $\mathrm{Zn} 35 \mu \mathrm{g} / \mathrm{dL}, \mathrm{Cu} 44 \mu \mathrm{g} / \mathrm{dL}$ ) (Fig. 2, arrow b). The patient was readmitted at the end of December 2005. To improve malnutrition, a CVC was re-inserted through the external jugular vein and injected with the MTE formulation and high-calorie infusions on consecutive days for 4 weeks (TP $5.9 \mathrm{~g} / \mathrm{dL}$, ALB $3.4 \mathrm{~g} /$ $\mathrm{dL}, \mathrm{Zn} 75 \mu \mathrm{g} / \mathrm{dL}, \mathrm{Cu} 47 \mu \mathrm{g} / \mathrm{dL}$ ). In January 2006, since her oral pain and diet had improved, she was discharged from the hospital after receiving an implant of a central venous port, and she continued home self-injection of MTEs to maintain zinc levels. In February 2006, her taste function tended to improve, and in April 2006, the taste almost improved. When MTEs were self-injected daily, the serum zinc level gradually exceeded the normal range and reached $167 \mu \mathrm{g} / \mathrm{dL}$ in August 2006 (Fig. 2 arrow c); therefore, the administration was switched to every other day. Subsequently, we had to confirm the blood test data repeatedly to monitor serum zinc levels to ensure that they were within the normal range (Fig. 2). Despite continuing intravenous zinc replacement therapy, serum zinc levels decreased when additional oral zinc was discontinued in May 2007. After resuming the oral administration

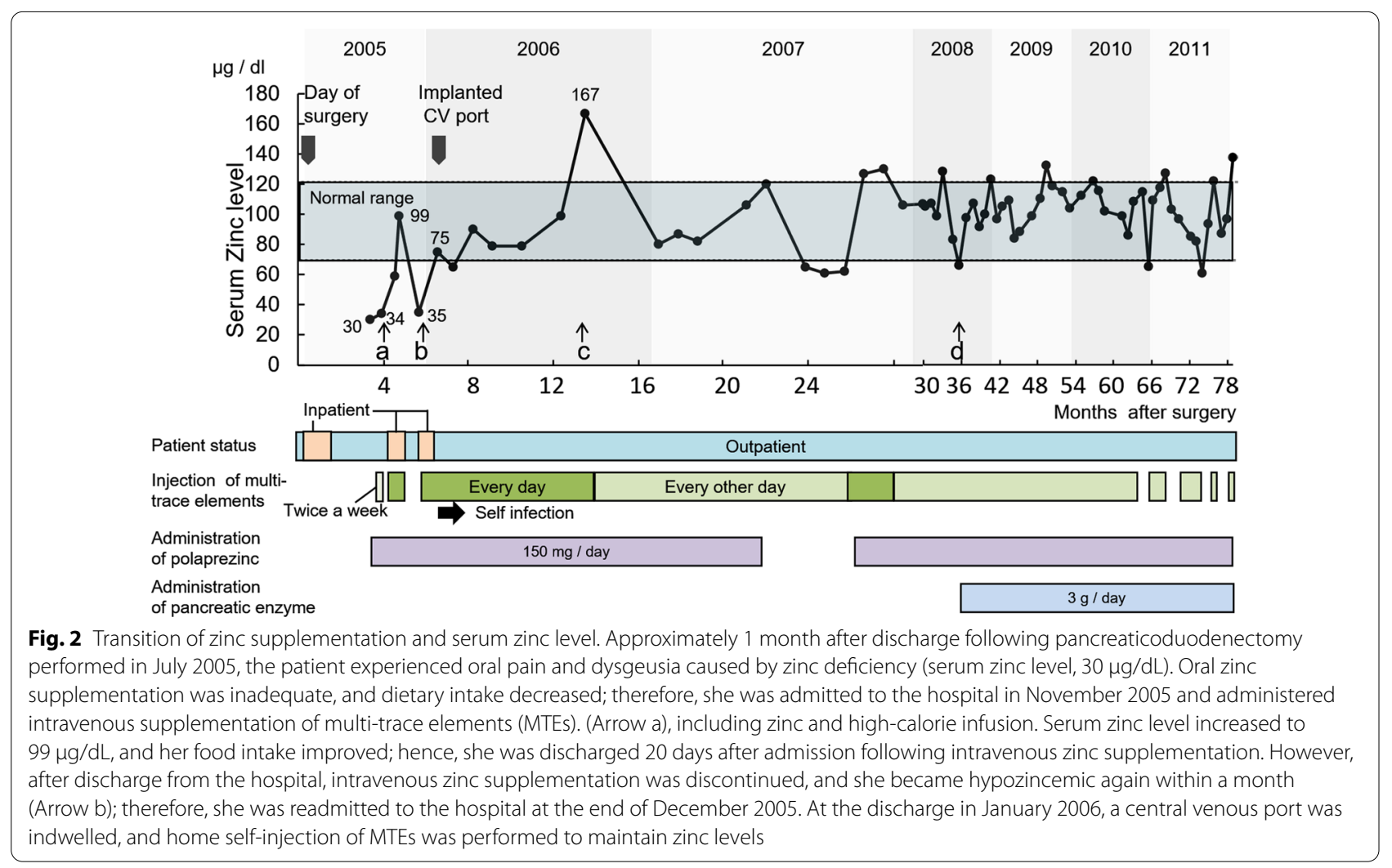


of Promac ${ }^{\circledR}$ due to the recurrence of dysgeusia, both the serum zinc level and dysgeusia improved. Since 2008, Pancreatin $^{\circledR}$ (pancreatic enzyme, Mylan Co Inc, USA) $3 \mathrm{~g} /$ day had been administered alongside conventional zinc administration for this patient (Fig. 2, arrow d).

As of January 2012, she continued using MTEs intermittently while her serum zinc values were monitored; however, slight angular cheilitis was observed, and she exhibited no signs of glossitis and dysgeusia (Fig. 1c). Moreover, recurrence and metastasis of the primary tumor were not observed. She subsequently died of lung cancer in May 2020.

\section{Discussion and conclusions}

There are few reports on postoperative taste loss in gastrointestinal cancer, and the involvement of zinc deficiency has not been investigated [16]. Since its introduction in 2002 at the Shizuoka Cancer Center Hospital, PD had been performed in approximately 45 patients per year until 2007; however, only the patient in this study experienced severe dysgeusia caused by zinc deficiency. In fact, dysgeusia and skin lesions caused by zinc deficiency following PD have not been assessed in quality-of-life studies [17-20]. The most common technique for PD consists of the en-bloc removal of the distal segment (antrum) of the stomach, the duodenum, the proximal part of the jejunum, the head of the pancreas, the common bile duct, and the gallbladder. Zinc is mainly absorbed in the duodenum and proximal jejunum, which are resected during PD, subsequently causing zinc deficiency. In the study by $\mathrm{Yu}$ et al. [13], one patient developed zinc deficiency with a serum zinc level of $32 \mu \mathrm{g} / \mathrm{dL} 15$ months postoperatively. During hospitalization, zinc was supplemented intravenously, and the patient was discharged after an oral administration of pancreatic enzymes; another patient developed zinc deficiency with a serum zinc level of $29 \mu \mathrm{g} / \mathrm{dL} 4$ years postoperatively. The patient required the continuous administration of zinc sulfate and pancreatic enzyme formulations [13]. In a study by Yazbeck et al., the patient developed zinc deficiency with a serum zinc level of $42 \mu \mathrm{g} / \mathrm{dL} 3$ years postoperatively. The patient was discharged after an oral administration of $50 \mathrm{mg} /$ day of zinc sulphate. Only in our case has oral zinc supplementation been inadequate, requiring continued intravenous zinc supplementation to maintain the normal serum zinc level. Although the details are unknown for other cases, the upper $15 \mathrm{~cm}$ part of the jejunum was surgically removed in this patient. Supposedly, conserved jejunum and ileum absorb zinc usually, and it is unclear why oral administration was inadequate in our case. Yu et al. and Yazbeck et al. proposed three mechanisms for zinc deficiency after
PD [13, 21]: (1) impaired zinc absorption associated with jejunectomy; (2) insufficient protein absorption after PD, which occurs because zinc is transported in the serum via carrier proteins, namely ALB (57\% of serum zinc), alpha-2-macroglobulin (40\%), and amino acids, such as histidine and cysteine $(<3 \%)$ [13]; and (3) impaired fractional absorption of zinc due to pancreatic insufficiency, which is improved by exocrine pancreatic replacement [22]. Consequently, poor protein absorption may cause low zinc availability. Moreover, deficiencies in branched-chain amino acids and essential fatty acids [13] may contribute to the formation of skin lesions similar to those of acrodermatitis enteropathica observed in patients with zinc deficiency [23, 24]. From a therapeutic viewpoint, the clinical manifestation of zinc deficiency in PD might be improved not only by supplementation with zinc but also by the administration of pancreatic enzyme formulations and adequate intake of protein and essential fatty acids [13].

At the time of this study, the gastric ulcer healing agent Promac $^{\circledR} 150 \mathrm{mg}$ could be supplemented with $34 \mathrm{mg}$ of zinc daily, while zinc replacement was an off-label use. In 2017, Nobelzin ${ }^{\circledR}$ tablet $50 \mathrm{mg}$ (zinc acetate hydrate 167.84 mg, Nobelpharma Co. Ltd., Tokyo, Japan), which had been proven to be safe and effective for the longterm treatment of Wilson disease [25], was approved for the additional indication of hypozincemia in Japan [26]. Currently, for zinc replacement therapy, three tablets of Nobelzin ${ }^{\circledR}$ could be supplemented with at most $150 \mathrm{mg}$ of zinc, which is more than four times as much zinc supplement as the standard dose of $150 \mathrm{mg}$ of Promac ${ }^{\circledR}$ daily. The difference in bioavailability between zinc acetate hydrate and polaprezinc is unclear; however, in a study of zinc supplement for hemodialysis maintenance patients, $50 \mathrm{mg}$ of zinc per day administered in the zinc acetate hydrate group was superior to $34 \mathrm{mg}$ of zinc per day administered in the polaprezinc group in increasing and maintaining serum zinc levels [27]. It is unclear whether higher oral zinc supplementation with zinc acetate hydrate could replace intravenous zinc supplementation in our case. A limitation of this study is that the findings are not generalizable. Further research elucidating the probable causes of zinc deficiency after PD is required to improve the generalizability of our study findings.

Zinc deficiency after PD rarely occurs, and the mechanism has not been fully elucidated; the clinical oncologist community, including dentists responsible for the oral care of cancer patients, should be aware of the oral adverse events, such as dysgeusia, glossitis and oral pain, associated with zinc deficiency after cancer surgery, as well as that induced by chemotherapy or head and neck radiation therapy. 


\section{Abbreviations}

PD: Pancreaticoduodenectomy; MTE: Multi-trace elements; CVC: Central venous catheter; TPN: Total parenteral nutrition; TP: Total protein; ALB: Albumin.

\section{Acknowledgements}

We would like to thank Miho Ota, the wife of Yojiro Ota, for consenting to the publication on behalf of the deceased (https://doi.org/10.1007/s00520-0131943-z). We thank Editage (www.editage.jp) for editing and reviewing this manuscript for English language.

\section{Authors' contributions}

All authors contributed to the study conception and design. The manuscript was drafted by $\mathrm{HH}, \mathrm{YO}$, and $\mathrm{KU}$. The data was acquired by MC, TM, KY, and $\mathrm{Kl}$. The analysis and data interpretation were conducted by $Y Y, T Y$, and YK. All authors read and approved the final manuscript.

\section{Funding}

No funding was received to assist with the preparation of this manuscript.

\section{Availability of data and materials}

All data generated or analyzed during this study are included in this published article.

\section{Declarations}

\section{Ethics approval and consent to participate}

This study was performed on human participants were in accordance with the ethical standards of the institutional and national research committee and with the 1964 Helsinki declaration and its later amendments or comparable ethical standards. Consent to participate was not applicable.

\section{Consent for publication}

Written informed consent was obtained from the patient's next of kin for publication of this case report and any accompanying images. A copy of the written consent is available for review by the Editor-in-Chief of this journal.

\section{Competing interests}

All authors have no conflict of interest to declare that are relevant to the content of this article.

\section{Author details}

${ }^{1}$ Division of Dentistry and Oral Surgery, Shizuoka Cancer Center Hospital, Shizuoka, Japan. ${ }^{2}$ Department of Dentistry and Oral Surgery, National Hospital Organization Hokkaido Cancer Center Hospital, Sapporo, Japan. ${ }^{3}$ Division of Hepato-Biliary-Pancreatic Surgery, Shizuoka Cancer Center Hospital, Shizuoka, Japan. ${ }^{4}$ Gerodontology, Department of Oral Health Science, Faculty of Dental Medicine, Hokkaido University, Sapporo, Japan. ${ }^{5}$ Department of Dental and Oral Surgery, Tomakomai City Hospital, Tomakomai, Japan. ${ }^{6}$ Faculty of Dental Medicine, Oral Diagnosis and Medicine, Hokkaido University, Sapporo, Japan.

Received: 18 November 2021 Accepted: 22 February 2022 Published online: 03 March 2022

\section{References}

1. Prasad AS. Impact of the discovery of human zinc deficiency on health. J Trace Elem Med Biol. 2014;28:357-63.

2. Santos HO, Teixeira FJ. Use of medicinal doses of zinc as a safe and efficient coadjutant in the treatment of male hypogonadism. Aging Male. 2020;23:669-78.

3. Bhattacharya PT, Misra SR, Hussain M. Nutritional aspects of essential trace elements in oral health and disease: an extensive review. Scientifica. 2016;2016:5464373.

4. Henkin RI. Zinc in taste function: a critical review. Biol Trace Elem Res. 1984:6:263-80.
5. Heckmann SM, Hujoel P, Habiger S, Friess W, Wichmann M, Heckmann $J$ G, et al. Zinc Gluconate in the treatment of dysgeusia - a randomized clinical trial. J Dent Res. 2005:84:35-8.

6. Sakagami M, Ikeda M, Tomita H, Ikui A, Aiba T, Takeda N, et al. A zinccontaining compound, polaprezinc, is effective for patients with taste disorders: randomized, double-blind, placebo-controlled, multi-center study. Acta Otolaryngol. 2009;129:1115-20.

7. Santos HO. Therapeutic supplementation with zinc in the management of COVID-19-related diarrhea and ageusia/dysgeusia: mechanisms and clues for a personalized dosage regimen. Nutr Rev. 2021.

8. Kinomoto T, Sawada M, Ohnishi Y, Yamaguchi T, Tsuge S, Ogawa S, et al. Effects of polaprezinc on morphological change of the tongue in zincdeficient rats. J Oral Pathol Med. 2010;39:617-23.

9. Kodama H, Tanaka M, Naito Y, Katayama K, Moriyama M. Japan's Practical Guidelines for zinc deficiency with a particular focus on taste disorders, inflammatory bowel disease, and liver cirrhosis. Int J Mol Sci. 2020;21:2941.

10. Hovan AJ, Williams PM, Stevenson-Moore P, Wahlin YB, Ohrn KE, Elting LS, et al. A systematic review of dysgeusia induced by cancer therapies. Support Care Cancer. 2010;18:1081-7.

11. Hambidge M. Human zinc deficiency. J Nutr. 2000;130:1344S-S1349.

12. Krebs NF. Overview of zinc absorption and excretion in the human gastrointestinal tract. J Nutr. 2000;130:1374S-S1377.

13. Yu HH, Shan YS, Lin PW. Zinc deficiency with acrodermatitis enteropathica-like eruption after pancreaticoduodenectomy. J Formos Med Assoc. 2007;106:864-8.

14. Armstrong T, Walters E, Varshney S, Johnson CD. Deficiencies of micronutrients, altered bowel function, and quality of life during late follow-up after pancreaticoduodenectomy for malignancy. Pancreatology. 2002;2:528-34.

15. Yu HH, Yang TM, Shan YS, Lin PW. Zinc deficiency in patients undergoing pancreatoduodenectomy for periampullary tumors is associated with pancreatic exocrine insufficiency. World J Surg. 2011;35:2110-7.

16. Welchman S, Hiotis P, Pengelly S, Hughes G, Halford J, Christiansen P, et al. Changes in taste preference after colorectal surgery: a longitudinal study. Clin Nutr. 2015;34:881-4

17. Huang JJ, Yeo CJ, Sohn TA, Lillemoe KD, Sauter PK, Coleman J, et al. Quality of life and outcomes after pancreaticoduodenectomy. Ann Surg. 2000;231:890-8.

18. Fong ZV, Alvino DM, Castillo CF, Nipp RD, Traeger LN, Ruddy M, et al. Health-related quality of life and functional outcomes in 5-year survivors after pancreaticoduodenectomy. Ann Surg. 2017:266:685-92.

19. Allen CJ, Yakoub D, Macedo FI, Dosch AR, Brosch J, Dudeja V, et al. Long-term quality of life and gastrointestinal functional outcomes after pancreaticoduodenectomy. Ann Surg. 2018;268:657-64.

20. van Dijk SM, Heerkens HD, Tseng DSJ, Intven M, Molenaar IQ, van Santvoort HC. Systematic review on the impact of pancreatoduodenectomy on quality of life in patients with pancreatic cancer. HPB (Oxford). 2018:20:204-15.

21. Yazbeck N, Muwakkit S, Abboud M, Saab R. Zinc and biotin deficiencies after pancreaticoduodenectomy. Acta gastroenterol Belg. 2010;73:283-6

22. Easley D, Krebs N, Jefferson M, Miller L, Erskine J, Accurso F, et al. Effect of pancreatic enzymes on zinc absorption in cystic fibrosis. J Pediatr Gastroenterol Nutr. 1998:26:136-9.

23. Kim YJ, Kim MY, Kim HO, Lee MD, Park YM. Acrodermatitis enteropathica-like eruption associated with combined nutritional deficiency. J Korean Med Sci. 2005;20:908-11.

24. Templier I, Reymond JL, Nguyen MA, Boujet C, Lantuejoul S, Beani JC, et al. [Acrodermatitis enteropathica-like syndrome secondary to branched-chain amino acid deficiency during treatment of maple syrup urine disease]. Ann Dermatol Venereol. 2006;133:375-9.

25. Shiomura J. Nobelpharma, a new Japanese pharmaceutical company that only provides medicines for unmet medical needs. J Thorac Dis. 2014;6:E125-9.

26. Katayama K, Hosui A, Sakai Y, Itou M, Matsuzaki Y, Takamori Y, et al. Effects of zinc acetate on serum zinc concentrations in chronic liver diseases: a multicenter, double-blind, randomized, placebo-controlled trial and a dose adjustment trial. Biol Trace Elem Res. 2020;195:71-81.

27. Okamoto T, Hatakeyama S, Konishi S, Okita K, Tanaka Y, Imanishi K, et al Comparison of zinc acetate hydrate and polaprezinc for zinc deficiency 
in patients on maintenance hemodialysis: a single-center, open-label, prospective randomized study. Ther Apher Dial. 2020;24:568-77.

\section{Publisher's Note}

Springer Nature remains neutral with regard to jurisdictional claims in published maps and institutional affiliations.

- fast, convenient online submission

- thorough peer review by experienced researchers in your field

- rapid publication on acceptance

- support for research data, including large and complex data types

- gold Open Access which fosters wider collaboration and increased citations

- maximum visibility for your research: over $100 \mathrm{M}$ website views per year

At BMC, research is always in progress.

Learn more biomedcentral.com/submissions 